\title{
Cine y psicoanálisis. Un ensayo sobre sus
}

\section{convergencias y bifurcaciones}

\author{
José Samuel Martínez López* y Gibrán Larrauri Olguín** \\ UNIVERSIDAd IBEROAMERICANA-CIUdAD DE MÉXICO
}

El cine y el psicoanálisis tienen un origen decimonónico. Tanto uno como el otro se deben a la propulsión científica y tecnológica que es factor de gestación del discurso de la modernidad, discurso que propone un avance progresivo y predecible hacia estados de mayor concordancia entre el sujeto y su mundo. Pero si bien el cine y el psicoanálisis son producto cultural de la modernidad, no por ello se podría indicar que son completamente afines a ella, o que incluso van en la misma dirección.

Palabras clave: Modernidad, cine, psicoanálisis, objeto a, subjetividad.

Cinema and psychoanalysis have a nineteenth century origin. Both are due to the scientific and technological propulsion which is factor for the gestation of the modern speech which proposes a progressive and predictable advance towards states of major consistency between the subject and his world. But even when film and psychoanalysis are products of cultural modernity that does not mean that both productions share its spirit, or even that they go in the same direction.

Key words: Modernity, cinema, psychoanalysis, object a, subjectivitiy.

\footnotetext{
* Maestro en Comunicación por la Universidad Iberoamericana-Ciudad de México, donde también labora como profesor investigador del Departamento de Comunicación, y funge como responsable del Área Académica de Investigación, así como coordinador editorial de la revista electrónica Comunicologi@. indicios y conjeturas (www.revistacomunicologia.org). Correos electrónicos: samjusto@yahoo.com y samuel.martinez@uia.mx

** Licenciado en Psicología por el Centro Cultural Universitario Justo Sierra. Actualmente colabora como profesor de asignatura en el Departamento de Comunicación de la Universidad Iberoamericana-Ciudad de México, y participa como responsable de edición de la revista electrónica Comunicologí@: indicios y conjeturas. Correo electrónico: larrauriol@yahoo.com.mx
} 


\section{INTRODUCCIÓN}

Dos cosas son las que se pretenden con este ensayo: en primer lugar, mostrar dónde y en qué convergen tanto el cine como el psicoanálisis; dos propuestas que coinciden en su afán por hacer emerger la incómoda verdad del sujeto moderno. En segundo término, lo que se busca con este trabajo es señalar que más allá de sus afinidades e inevitables convergencias, el cine - considerado como el único arte del cual conocemos su fecha de nacimiento- - y el psicoanálisis se bifurcan de manera epistemológica en el sentido en que mientras el arte-industria del cine dicta perversamente historias a las masas, aspira a expresarlo todo y construye por múltiples vías los avatares del deseo de los sujetos, el psicoanálisis, buscando desplazarse del lugar del amo, más bien señala la imposibilidad de hacer una historia total y terminante de los sujetos. Como lo diría Zizek en "The pervert's guide to cinema" (Fiennes, 2006): el cine es un arte perverso pues no puede evitar no insinuar cómo habría que desear, no puede no decir cómo vive alguien ya sea en lo individual y/o en lo grupal su búsqueda del objeto perdido. Nada más alejado del psicoanálisis para quien el objeto del deseo está, de entrada, perdido, es inefable e inasible y, por ende, el señalamiento de tal objeto, o la mera sugerencia de cómo se debería conquistarlo, es una impostura.

Estructurado en seis progresivas partes, este texto tiene como fin demostrar el vínculo, las coincidencias y el desencuentro entre estos dos significativos productos de la modernidad, y puntualizar que el objeto epistémico que propicia la praxis de ambos no es tanto la subjetividad, sino "lo que falta" en todo sujeto: aquello que lo empuja a experimentar el malestar y lo condena a mantenerse en estado de permanente búsqueda. Tal reflexión nos lleva de manera natural a preguntarnos, en la parte final de este ensayo, por el futuro y los destinos del cine en tanto eje de la pantalla global, púlpito para el culto a lo hipervisual y matriz de lo imaginario mediático. Y es que guste o no, en el marco de la actual sociedad de la información (de la modernidad líquida), pero sobre todo gracias al llamado capitalismo de ficción y al hiperconsumo generalizado que éste ha desatado, en los últimos años se ha conformado y extendido una verdadera pantallocracia - como dirían Lipovetsky y Serroy-, cuyo obsceno discurso y omnipresente textualidad, además de haber sido moldeados bajo el régimen estético-narrativo de lo cinevisual, implican una negación brutal de lo real y un sintomático enamoramiento de lo virtual. 
Para poder llevar a cabo una reflexión que despliegue los puntos de encuentro y de desencuentro entre el psicoanálisis y el cine, es necesario, en primer lugar, delimitar el contexto histórico-teórico (inevitablemente decimonónico) del cual estos dos fenómenos culturales proceden. Desde luego, es importante señalar que resulta necesario ubicar su perímetro histórico de gestación no con la intención de ofrecer sólo datos y anécdotas pintorescas que muestren los vínculos entre estas dos disciplinas, sino con el objetivo de enmarcar su cercano nacimiento y entrecruzamiento a nivel epistémico.

En otros términos, si hemos decidido comenzar este ensayo sobre psicoanálisis y cine con un apartado que verse sobre el "positivismo" y los presupuestos de la "era moderna", es en correlación a que, para nosotros, tanto cine como psicoanálisis no son productos "positivistas", sino su vórtice negativo: efectos "no intencionales" del positivismo" moderno, manifestaciones que a contracorriente pusieron en jaque los preceptos de la ciencia formal y sus aspiraciones de centrar el devenir humano con base en la razón.

Como se sabe y es reconocido por un buen número de historiadores, lo que se ha optado por llamar modernidad "es un efecto del discurso de la ciencia, de ese discurso que surge en los siglos XVI y XVII asociado a los nombres de Galileo y Descartes" (Gerber, 2005, p. 87). Se trata de un discurso filosófico que, entre otras cosas, sugiere (cogito ergo sum) la reducción de la subjetividad humana a la esfera de lo racional.

Históricamente, y como bien lo señaló Foucault en Las palabras y las cosas, el movimiento epistemológico con el cual se logró colocar a la razón (y la ciencia) como el eje del proyecto moderno, está vinculado con el paso del estudio (en voz alta), comentario (oral) y cotejamiento (sustentado en la fe) de la palabra divina en el mundo premoderno, a su examen, crítica y cuestionamiento racional (a través de la escritura) a partir de la producción de verdades metódicamente construidas en los diversos campos del saber. De ahí que se afirme que

Surgimiento de la modernidad, nacimiento de la ciencia moderna e imperio de la razón son fenómenos íntimamente vinculados. El punto de origen puede situarse en Descartes, específicamente en su cogito: "pienso, luego soy".

${ }^{1}$ El positivismo es una corriente o escuela filosófica que afirma que el único conocimiento auténtico es el conocimiento científico, y que tal conocimiento solamente puede surgir de la "afirmación positiva" de las teorías a través del método científico. 
Con él se establece el predominio de la razón, que se basa en una transferencia de responsabilidades: de Dios al hombre. (Gerber, 2005, p. 93)

Amparado de manera irremisible en el saber de la ciencia y declarando abiertamente su esperanza en el progreso tecnológico, el discurso epistémico de la modernidad (supuestamente secular y vacunado contra todo tipo de mitos e ilusiones trascendentales), al fetichizar y sobredotar a la razón de un gran poder, lo que en el fondo posibilitó fue el paradójico surgimiento de una nueva fe, de un mito, de una ilusión utópica: la fe en el progreso (guiado durante un tiempo por el Estado y hoy por la mano invisible del mercado); la fe en una, por lo demás, mítica sociedad sin mitos; en una utópica sociedad sin utopías. Hablamos de un tipo de fe que continúa abrevando del discurso cientificista que prometió un "verdadero renacimiento" de la humanidad, así como la posibilidad de un progreso inevitable y armónico que por fin vendría a acabar con la discordia del ser humano con su mundo y del sujeto consigo mismo:

Por esto se puede decir que el mundo moderno, el mundo que se inicia en el siglo XVIII es un efecto del discurso de la ciencia. Es un mundo que se organiza con base en el saber y la razón y se sustenta en el dogma del progreso. Este último se define como la evolución hacia estados de cada vez mayor dominio sobre la naturaleza y armonía entre los hombres que pueden alcanzarse por medio del saber. (Gerber, 2005, pp. 94-95)

El saber positivo y su marco filosófico fueron entonces los que, desde el principio, nutrieron, forjaron y todavía acompañan al proyecto moderno. Hablamos del sueño positivista de reducir la incertidumbre por vía de la razón tecnocientífica, y de amplificar el control y el dominio cognitivo del entorno (su domesticación) gracias a la razón formalizadora e instrumental, todo como premisa para anticiparse a los problemas y supuestamente garantizar una vida emancipada, feliz y plena; rebozante en prosperidad y duración, en salud y educación, en paz social, avenencia y democracia. En otras palabras, la modernidad ha sido la época que discursivamente se ha autopromovido como el tiempo secular de una esperanza y libertad sin precedentes; de hecho, se autodeclara como la época con la mejor estructura social posible; la época donde la felicidad y la diversión son prácticamente una obligación ciudadana y el conocimiento científico "en principio" puede formalizar, comprender y resolverlo todo, o casi todo. En palabras de Gérard Pommier:

Entre el siglo XVIII y el siglo XX, la gente se entusiasmaba con la cercana emancipación de la humanidad. La idea de un progreso continuo secularizaba 
el relato cristiano de la redención del error de Adán. Ya sea gracias a la ciencia, que triunfaba sobre la ignorancia, que rompía las cadenas del feudalismo, que ponía fin a la explotación capitalista o, por el contrario, que apostaba al capitalismo para vencer la pobreza, siempre se trataba de llevar a cabo una historia que culminaría en la felicidad y la libertad. (Pommier, 2000, p. 9)

Evidentemente, aunque hoy sea más fuerte que nunca y en el discurso se siga sosteniendo la ilusión de un progreso infinito, dicho programa que llevaría eventualmente a un "final feliz", al cálculo y al conocimiento pleno o total de la verdad del mundo humano y natural, ha demostrado, en muchas ocasiones, sus límites. Y es que si bien es cierto que la ciencia moderna ha avanzado, nos ha ayudado a comprender y enfrentar de mucho mejor manera algunos problemas técnicos, nos ha permitido de alguna forma mitigar la incertidumbre del entorno y ha podido otorgar a cierto sector de la humanidad la posibilidad de una vida más práctica, confortable y segura, en el plano general esta briosa forma de conocimiento no ha sido capaz (ni lo será) de asegurarnos una vida liberada del peso de lo trágico, lo doloroso, lo incalculable, lo imprevisto, lo azaroso, lo enigmático y lo inconsciente mismo.

Hay que aceptarlo: en los últimos 400 años, el método de la ciencia, que comparte con otros saberes los límites propios del lenguaje humano, ha demostrado que es incapaz de aprehender y comprender la verdad humana en toda su plenitud, aquella que tiene su sede en la dimensión más radical de la existencia: el deseo. ${ }^{2}$ Y no lo ha podido hacer porque el deseo, además de que se resiste a ser apresado por el lenguaje, habita en el fondo de las propias subjetividades y es el índice de una imposibilidad de formalización plena. De ahí que no se trate de ninguna casualidad que junto con la subjetividad, sea precisamente el deseo - siempre imprevisto, enigmático, riesgoso e indomesticable — lo más soslayado y ninguneado por la ciencia; aquello que ésta, con toda su racionalidad, no ha podido formalizar, y de lo que no puede saber porque es de carácter inconsciente; aquello que reprime y cuya indomable existencia no se atreve a reconocer a pesar de que paradójicamente es lo que en el fondo nutre la pulsión epistémica que gatilla la curiosidad de todo científico, así como su anhelo

\footnotetext{
2 ¿Qué se entiende por deseo? Desde el punto de vista del psicoanálisis, por "deseo" se entiende una moción psíquica a partir de la cual el sujeto busca infructuosamente reestablecer la situación de la satisfacción primera (Gerber, 2009, p. 104). Una moción que aunque aspire al goce y la satisfacción total, por estar ligada a representaciones, por provenir de una irremediable falta y por estar contenida por la ley, siempre fracasa y así mantiene recursivamente la posibilidad de seguir buscando aquello que por fin pueda colmarla.
} 
de trascendencia y sus ansias de reconocimiento. Marcando un límite infranqueable, el deseo es aquello de lo que la misma ciencia nada quiere saber; una verdad que surge a pesar de ella.

Y es justo en este punto, en el corazón positivista de la propia maquinaria científica moderna, que como respuesta a las tentativas de uniformizar la subjetividad, domar el deseo, calcularlo y formalizarlo todo, emergieron distintas manifestaciones culturales que fluyeron en sentido contrario ${ }^{3}$ a los preceptos racionales modernos. Desde luego, entre estas distintas manifestaciones que surgieron para mostrar y darle un espacio al deseo y a la singularidad del sujeto, se encuentran los dos campos que aquí nos interesan: el psicoanálisis y el cine.

Nuestra lectura es que la crítica radical que estas dos manifestaciones han estado inflingiendo al propio discurso moderno durante ya más de cien años, parte de señalar que aunque avance, disminuya parcial y momentáneamente la incertidumbre y mantenga viva la ilusoria esperanza de algún día lograr conocerlo, controlarlo y determinarlo todo, la ciencia simplemente "no puede". Pero ¿qué es lo que no puede? Como ya lo comentamos, no puede calcular ni formalizar aquello que desde cada científico y/o tecnólogo la determina e impulsa: el deseo. Y por ello podemos afirmar que aunque la ciencia busque colmar con saber, por fin, la falta ${ }^{4}$ que ontológicamente nos distingue y hace sujetos escindidos, nunca podrá suturarla ni saturarla; y por lo mismo, aunque prometa que algún día producirá un volumen de conocimiento tal que podrá hacer que el sujeto entre en armonía o complementariedad consigo mismo y con su mundo, por cuestiones estructurales inherentes a la castración, la convivencia y el lenguaje, la ciencia nunca podrá evitar que vivamos la experiencia del malestar en la cultura.

Pero para comprender bien la impugnación y la crítica que de alguna manera el cine ejerce de forma implícita y el psicoanálisis despliega de manera explícita contra la racionalidad moderna, resulta clave distinguir la diferencia entre las categorías psicoanalíticas de "saber" y "verdad".

\footnotetext{
${ }^{3}$ Hablando específicamente del cine, algo que evidencia muy bien este tipo de paradojas es el camino insospechado que este invento tomó. Así al menos lo ilustra la siguiente anécdota compartida por Lipovetsky y Serroy (2009, p. 32): “cuando los hermanos Lumière ponen el cine a punto, lo hacen como industriales, no como artistas, y lo demuestra lo primero que filman: la salida de los obreros de la fábrica", con lo cual se demuestra que en el caso del cine, el arte no creó la técnica sino que fue la técnica la que sentó las bases e inventó al arte.

${ }^{4}$ Origen y atolladero del deseo, por "falta" entendemos aquí la humana experiencia de la incompletitud y el desajuste entre el sujeto y su mundo; la permanente sensación de la insatisfacción humana; la vivencia del malestar en la cultura; la perenne y periódica percepción de que algo no anda bien o no marcha tal y como lo deseamos.
} 
Para comprender la cuestión del saber, vale la pena recordar algo comentado por Heidegger, quien al hablar del saber científico alguna vez dijo: "la ciencia por su lado no piensa, y no puede pensar" (1967, p. 16). ¿Qué significa esto? Por una parte, que el saber de la ciencia, por ser instrumental y utilizar el lenguaje referencial, no se permite "pensarse a sí misma, pensar su esencia, dándose como única posibilidad de pensar la de funcionar" (Lebrun, en Aceituno \& Rosas, 1999). Y por otra parte, que la ciencia produce un tipo de saber que no le permite conocer la "verdad" inevitablemente psíquica que anima y, según el psicoanálisis, delinea la vida de todo sujeto. Se trata sí de un saber técnico que formaliza, calcula y determina al mundo tangible, pero que paradójicamente desconoce $\mathrm{u}$ omite de dónde proviene su propia pasión de producción epistémica. Dicho de otra manera, el saber científico no tiene los elementos suficientes para responder, a fondo, la siguiente pregunta relacionada con el deseo de conocer y la curiosidad de los propios investigadores: ¿Por qué ciertas subjetividades se comprometen y embarcan en un proyecto científico? A pesar de que en muchas ocasiones se ha hecho un esfuerzo por ofrecer respuestas "objetivas" a esta pregunta, sin atreverse a cruzar el fino borde que separa lo racional formalizable de lo inconsciente-reprimido, estas disciplinas en la mayoría de los casos se han quedado cortas. Hablamos de algo grave y sintomático, sobre todo si se toma en cuenta que dicha pasión por conocer se origina, precisamente, en el deseo inconsciente (de los propios científicos) y la pulsión de saber que lo representa. En palabras de Pommier:

La pulsión de saber aborda en el exterior aquello que la pulsión como tal sacia en el cuerpo. Corresponde, del lado del sujeto de la ciencia, a la pulsión sin más, fundamento del sujeto del inconsciente [...] La pulsión de saber impondrá sin duda su regla, pero al precio de un desconocimiento en cuanto a su lugar de origen. Es preciso saber, pero sobre todo no saber en qué consiste aquello que empuja hacia allí. De modo que el hombre puede aprender mucho acerca del movimiento de las estrellas, a un tiempo que ignora lo esencial del movimiento de su deseo. (Pommier, 2005, p. 90) (las cursivas son nuestras).

Nos estamos refiriendo a una singular crítica a partir de la cual, sin duda, se fundó/desplegó el psicoanálisis y, de alguna u otra forma, también el cine (el único arte que según Muray, por haber nacido después de haberse declarado la muerte de Dios, no ha tenido que emanciparse de lo religioso). Hablamos de una crítica que tiene su origen en la incapacidad de la ciencia para construir lo que Freud llamó una Weltanschauung, es decir, una "visión del mundo". 
Está crítica del psicoanálisis y del mismo cine versa sobre el hecho de que la ciencia deja fuera, margina y trata como un residuo pernicioso al deseo, justo cuando de lo que se trataba era de satisfacer ese deseo. Sin embargo, la ciencia, paradójicamente, a través de su corazón positivista, magnifica la verdad que señala que para el deseo no hay objeto, cálculo o determinismo que le valga como posible complemento/cumplimiento. Y es, pues, de esta verdad psíquica que nos parece lícito afirmar que el psicoanálisis y el cine son productos culturales negativos de la modernidad. Más claro aún: el psicoanálisis y el cine construyen su sentido y su razón de ser a partir de ocuparse, precisamente, de aquello de lo que la ciencia nada quiere saber; algo que, desde luego, no es cuestión de casualidad, sino de estructura.

\section{2) Cine y psicoanálisis: "lo que no anda" dentro de la modernidad}

Hace unos años, el psicoanalista francés Roger Dadoun señaló las coordenadas gemelas que hacen del psicoanálisis y del cine disciplinas convergentes, ambas a contrapunto de la matriz filosófica y científicoinstrumental que paradójicamente posibilitó su gestación:

Nunca se lo dirá lo bastante, puesto que aparentemente se tiende más bien a repugnar su reconocimiento: es sorprendente ver a qué punto psicoanálisis y cine hablan un lenguaje vecino sino es que común, recorren y cavan los mismos terrenos, el psicoanálisis mediante la palabra y la conceptualización, el cine mediante la imagen y la puesta en escena. (Dadoun, 2000, p. 13)

La hermandad entre los dos campos y las dos visiones que aquí nos interesan, no tiene que ver sólo con la similitud de lenguajes metafóricos que comparten entre sí o con el hecho de que son espacios construidos para que emerja lo que "no anda en la modernidad", sino que existen razones históricas que las vinculan. Como bien lo expresó la especialista Bárbara Creed:

El psicoanálisis y el cine nacieron al final del siglo diecinueve. Ambos comparten antecedentes históricos, sociales y culturales comunes formados por las fuerzas de la modernidad. Los teóricos comúnmente exploran cómo el psicoanálisis, con su énfasis en la importancia del deseo en la vida del individuo, ha influido en el cine. Pero lo opuesto también es cierto-el cine bien pudo haber influido en el psicoanálisis. Freud no sólo trazó la descripción de sus teorías a partir de términos cinematográficos, como con el concepto de "recuerdos encubridores", sino que también desarrolló una cantidad de sus 
ideas fundamentales en términos visuales_-particularmente en la teoría de la castración, la cual es dependiente a partir del shock registrado por el acercamiento en primer plano de los genitales femeninos. (Creed, 1998)

Se trata de un vínculo que, como ya señalamos, aunque parezca obra de la coincidencia, se presentó como consecuencia imprevista y hasta negativa del clima positivista de la época; un vínculo producto de la propia historia dialéctica del pensamiento humano. Hablamos de la gestación de dos grandes productos culturales que emergieron en el cenit del pensamiento moderno, justo a finales del siglo XIX y principios del XX. Para ser más precisos, en el año de 1895, que, como ha recordado el mismo Dadoun, fue el año que

... ve aparecer el primer libro de Freud, Estudios sobre la histeria, escrito en colaboración con Breuer, es también el año que comúnmente se retiene como aquel que marca la llegada del cine a la civilización contemporánea: las patentes Lumière son del 13 de febrero de 1895, y la primera proyección del Cinematógrafo Lumière tuvo lugar el 28 de diciembre del mismo año en el Grand Café, en París. Tal fenómeno cultural de nacimiento gemelo ofrece más que una anecdótica coincidencia, se revela como el fruto de búsquedas caracterizadas por un paralelismo sorprendente. Antes de avocarse de manera decisiva sobre la patología, Freud se entrega a laboriosos trabajos de fisiología (neuronas, médula, cocaína, etc.) dentro del espíritu positivista de la época que tenían las ciencias físicas por modelo. Es dentro de un mismo espíritu, y a partir de las gabinetes de física y de los laboratorios, que físicos y fisiólogos, tales como Plateau, Muybridge, Marey, Edison y otros, construyen dispositivos y aparatos con el objetivo de descomponer, de analizar el movimiento de los seres vivos (hombre, caballo, etc.), de perforar ese secreto familiar que es la dinámica de los cuerpos. (Dadoun, 2000, p. 23)

Ahora bien, una cosa que cabe recordar y puntualizar aquí, es que si bien es cierto que el psicoanálisis y el cine deben su existencia al movimiento positivista científico que contribuyó al despliegue de la modernidad, éstos, de forma infiel, no siguieron mecánicamente sus mismos preceptos. Tanto, que incluso se puede afirmar que desde que nacieron avanzan en sentido opuesto al positivismo, como bien lo demuestra el hecho de que cada uno, desde su trinchera (el diván/espacio analítico y la pantalla/sala oscura de proyección) y por sus propios medios (la palabra y la imagen), apuntan a destituir la fuerza (o al menos a ponerla en jaque) de la que, como productos de la cultura decimonónica, se nutrieron: 
Particularmente sugestivo es el hecho de que esos desarrollos de origen, de envergadura y de vocación científicas se pongan casi bruscamente a bifurcar luego que disponen, en ese final del siglo XIX, de un aparato conceptual (el psicoanálisis) o de un aparato tecnológico (el cine): llamado que es también lanzado, mediante dos vías radicalmente diferentes, el inconsciente, los sueños, los fantasmas, las imágenes, las ficciones, la emoción, lo maravilloso [...] Todo ocurre como si el cine y el psicoanálisis, sirviéndose de un mismo movimiento subversivo contra la trayectoria científica que los contenía, manifestaran el deseo de torcerle el cuello a una cierta retórica positivista, para abrirle al hombre imaginario de la era moderna sus dos perspectivas paralelas; como si las brillantes claridades del iluminismo racionalista del siglo XVIII, mediante una nueva fidelidad y como reencontrado al principio del placer alojado en su corazón libertino, descubrieran el camino de las salas oscuras, el dejarse llevar y dejar hacer de los estados hipnoides, la penumbra crepuscular del alma sobre el diván analítico. (Dadoun, 2000, pp. 23-24)

Entre otras cosas, esto se presentó así porque a diferencia de los constructos empíricos con los que de forma instrumental se enfrenta el positivismo, el psicoanálisis y el cine trabajan y se concentran, sobre todo, en destacar y hacer emerger la singularidad del sujeto. A contracorriente de lo que hace la ciencia cuando para conocer o aproximarse a una verdad "objetiva" sobre los seres humanos y su entorno, renuncia a lo subjetivo, fragmenta/totaliza, uniformiza/homogeneiza y equipara/compara, el psicoanálisis y el cine, yendo caso por caso e historia por historia, prefieren trabajar con la particularidad y la complejidad de la experiencia humana; se esfuerzan en mostrar, en exponer sin tapujos la subjetividad, la incógnita que nos mueve. En otras palabras, a diferencia del discurso científico que presume de producir conocimientos válidos y universales y sueña con la posibilidad de reducir la incertidumbre y conquistar algún día el conocimiento total de las cosas, las propuestas epistémicas del psicoanálisis y el cine se distinguen por develar lo singular, lo impar, lo que a ojos de la ciencia parece extraño, incontrolable e imposible de formalizar. Esto es, si del lado de la ciencia se trata ante todo de abstraer y sintetizar la complejidad de los fenómenos para facilitar su predicción y control, del lado del psicoanálisis de lo que se trata, como su nombre lo indica, es de psico-analizar, de dividir en sus partes la totalidad de una subjetividad dada.

Porque no puede con el deseo, lo reprime y renuncia a él, desde el punto de vista de algunos expertos en psicoanálisis, la ciencia (sobre todo cuando se reviste de cientificismo) no puede ser ya percibida como un espacio infalible para la producción de saberes instrumentales encaminados a garantizar una vida más confortable y un progreso armónico, sino 
como un proyecto epistemológico que llevado a su extremo implica la posibilidad real del exterminio del propio deseo humano (como deseo de deseo), esto es, de lo más íntimo de la subjetividad, aquello que le da su impronta a todo sujeto:

Eliminación radical de lo Otro para imponer el dominio de lo mismo como dimensión universal: tal sería el programa del discurso de la ciencia. Por esto el propósito de lograr la uniformidad, para lo cual la ciencia homogeneiza el mundo, disuelve las familias amplias, las colectividades, tiende a borrar las particularidades y las diferencias. En el horizonte se encuentra la desaparición de la alteridad, ante todo la del sujeto consigo mismo. El sujeto debe volverse enteramente calculable, previsible. (Gerber, 2005, pp. 87-88)

El cine, por su parte, es al mismo tiempo una forma de expresión estética y una industria que no muestra otra cosa que precisamente la alteridad de las cosas, la magia de los movimientos fugaces o el ser que se dispersa en cuanto se muestra. Como bien lo indicaron recientemente Lipovetsky y Serroy (2009, p. 9):

... el cine se construyó de entrada a partir de un dispositivo figurativo totalmente moderno e inédito: la pantalla. No el escenario teatral ni la tela del cuadro, sino la pantalla iluminada, la gran pantalla, la pantalla en la que se muestra la vida en movimiento [...] La pantalla no es sólo un invento técnico integrado en el séptimo arte: es ese espacio mágico en el que se proyectan los deseos y los sueños de la gran mayoría.

Desde luego, aunque se base en el ojo/visión y determine al sujeto que lo observa; aunque se base en una técnica moderna y tenga una finalidad también moderna, el cine no hace ciencia, no hace cálculos ni intenta reducir la singularidad o la alteridad a un grado cero de mismidad y ninguneo, sino que se encarga de mostrar y captar precisamente ese infinito calidoscopio de alteridad en la que los sujetos y su cultura son los actores principales, los prot-agonistas, los seres patológicos —en el sentido kantiano- que se mueven en una búsqueda infinita en los rieles del deseo inconsciente.

El psicoanálisis y el cine son, pues, partidarios de una ideología cuya ética no es la de lo universal, sino la de lo singular e irrepetible, lo que como ya hemos dicho, de facto los coloca en el extremo opuesto de lo que busca conquistar la ciencia moderna, cuya ideología es la del "hombre-máquina, o la máquina-hombre (como mejor te parezca)". Vamos, como dijo Pommier (2000, p. 41), aunque no se acepte, la ciencia, en el fondo, lo que busca es 
“iterminar con la subjetividad, con el deseo, con la libertad!”. Es como si dijera: "¡cómo ya no sabemos qué hacer con todo eso, mejor terminemos con ello!".

\section{3) Lo "real" del cine: el objeto a llevado a la pantalla grande}

Partimos en este punto considerando la siguiente afirmación de Aristóteles: las imágenes son como las cosas sensibles mismas, excepto que no tienen materia. Afirmación con la que declaramos estar parcialmente de acuerdo, pues pensamos que si bien es cierto que las imágenes "no tienen materia", sí cuentan con una causa, o mejor dicho, con un componente intrínseco a ellas y que es menester subjetivar; algo que pone en tela de juicio la ausencia de materia de las imágenes. Dicho componente es lo que desde el psicoanálisis lacaniano se denomina como lo real.

Hay que dejarlo claro: lo real, de acuerdo con Jacques Lacan, no es sinónimo de realidad (de mundo material, tangible) ni de verosimilitud, sino que más bien es aquello que la realidad no puede simbolizar; aquello que la subjetividad nunca puede acaparar del todo. Aún más radical, para el psicoanálisis de corte lacaniano lo real no es algo exterior a la subjetividad, sino aquello que le da su fundamento. Así pues, lo real está del lado de la verdad psíquica, de la angustia, y siendo más extremos: lo real está del lado de la muerte; detrás de las cosas. Es decir, detrás de la cogitación está lo real como lo encargado de impulsar la subjetivación misma del mundo. O para decirlo de otra manera: lo real se podría vincular muy de lleno con el ser que se muestra inefable. Como alcanzó a vislumbrar Aristóteles, en toda imagen hay esa presencia de lo real; hay un punto en que las palabras faltan para significarla.

A partir de esta importante distinción, en torno al cine (aunque también puede hacerse extensivo para toda forma de expresión artística) afirmamos que su objeto de inspiración, su objetivo y razón de ser, consiste en mostrar lo que no se deja formalizar. Como lo afirma Maier: "El 'objeto' del arte no es algo que se pueda tocar; es una inversión pura" (Maier, 2005, p. 89). ¿Por qué lo dice? Porque es precisamente lo real lo que funciona como autor latente de toda producción creativo-expresiva.

Para comprender mejor la afirmación anterior, vale la pena tomar en cuenta que lo real, junto con lo simbólico y lo imaginario, constituyen los tres registros que, de acuerdo con Jacques Lacan, dan consistencia al psiquismo humano. Lo simbólico habría que definirlo como el lenguaje, la "herramienta" que se apodera del organismo humano y que permite el despliegue del sentido (de la cultura); aquello que por la vía de la semiosis nos separa del orden de la animalidad y del mero instinto. Lo imagina- 
rio, por su parte, es comúnmente entendido como la imagen a secas, aunque como sabemos, ninguna imagen es eso y punto, ya que siempre aparece tocada/cruzada por lo simbólico, y también es subsidiaria del engaño o la trampa del sentido, pues lo que se ve no siempre es lo que es. Y lo real, como ya lo comentamos arriba, es "lo excéntrico", tanto a lo simbólico como a lo imaginario; no es un más allá, sino aquello que el lenguaje y la imagen no pueden mostrar porque, en efecto, se constituyen a partir de ese real innombrable. Provocadora y contradictoriamente, para Lacan $l o$ real es así: el vacío, el lugar de la fuga, y a la vez, es materialidad suprema.

Una metáfora puede aquí ser muy útil para comprender lo antes expuesto: la de la célebre vasija comentada por Heidegger. El vacío de la vasija no es sólo el lugar en donde algo puede verterse, sino que es la condición misma del entramado que le da consistencia a las paredes de la vasija. Y ésta es justamente "la función" de lo real: aquello que queda excluido para que el resto tome consistencia. De aquí que se afirme que lo real siempre se nos presenta muy emparentado con la cosa y con el ser, es decir, con un algo más allá de los objetos y el mundo tangible; con un algo más allá y tal vez más acá, de la ex-sistencia misma, o sea, la esencia inefable de las cosas del mundo y de la vida.

Así lo reiteró Lacan: "de lo imaginario, lo simbólico y lo real, uno de los tres, lo real ciertamente, puede caracterizarse precisamente por lo que dije: por no conformar un todo, es decir, por no cerrarse" (1988, p. 97). Y es gracias a la cualidad de abertura de lo real que la creación-transgresión artística puede desplegarse y ver la luz. De hecho, podemos colegir que la creación no se hace más que a partir de la ausencia, y la ausencia desde el psicoanálisis es aquello que usa los ropajes de lo real, puesto que se trata de la ausencia de un objeto que pudiera, definitivamente, colmar el deseo.

Hablando del deseo, antes de seguir se impone referirnos a ese otro concepto hermano de lo real con el que Lacan designó el objeto que simbólicamente causa todo deseo, es decir, el objeto $a$. ¿Qué quiere decir esta expresión? Cuando se habla del objeto $a$ no se habla de una cosa concreta, sino, ante todo, de una representación, de una cadena interminable de significantes, de una aspiración que se caracteriza por ser nada. Y es que para Lacan, este objeto $a$ que causa el deseo y promete ser la gran satisfacción, por estar ligado a signos y representaciones, es un objeto que se halla al principio de la cadena metonímica que organiza las búsquedas del sujeto con su parte resignada (el ser) en pro de la cultura. Se trata de un objeto camaleónico, indefinido, que aunque promete ser el gran objeto que procurará por fin el goce, todo el tiempo muta de rostro, cambia de lugar, y siempre se halla delante de nosotros; un objeto que no existe y que no cuenta entre las cosas del mundo, pero cuya incesante 
búsqueda empuja al sujeto a realizar rodeos incesantes, a emprender y repetir búsquedas permanentes e infructuosas. En suma, la expresión objeto $a$ se usa para referirse a aquellos objetos (un auto, una casa, un iPod, una imagen religiosa, un título académico, etcétera) que Lacan llamó "letosas" en su seminario El reverso del psicoanálisis, y en los que por detrás de la excitación visual y sensorial respira intacto el fantasma de una satisfacción irrealizable. En palabras de un experto local, el objeto $a$ es aquello "que causa el deseo y motoriza la pulsión" (Braunstein, 1999, p. 63); es un objeto imposible de existir, pero que nos condena a buscar lo que siempre se perfila inasequible.

No se olvide que según el psicoanálisis, todo ser humano, por estar subordinado al lenguaje, está en falta, está escindido entre aquello a lo que tuvo renunciar (el mítico goce primigenio total) para advenir (por vía del lenguaje y la castración) como sujeto en el seno de la cultura. Para decirlo de una manera mucho más convencional: todo sujeto está dividido entre el ser y la nostalgia por recuperarlo; por ello, podría afirmarse que el deseo (todo deseo) es deseo de deseo, y que el objeto $a$ es aquello huidizo e indefinido que se esconde detrás de todas las cosas de este mundo.

De acuerdo, entonces, con nuestro recorrido psicoanalítico, el objeto $a$ es el objeto inspirador, aquel que propicia la sublimación, aquel que se intenta enmarcar y conquistar, pero que siempre se escapa. Y es lo real, más no la realidad, la materia prima con la que todo artista trabaja. De ahí que se pueda enunciar que todo acto creativo es un intento corajudo que se topa irremediablemente con un límite y este límite es lo real, "lo que no cesa de no escribirse" (Lacan, 1981, p. 114). Hablando específicamente del cine, Dadoun nos lo recuerda muy bien cuando señala que "El cine es, ante todo, holding, sostén de lo real" (2000, p. 9), y en particular cuando de manera enfática señala que "En el cine, es lo real lo que funciona como pantalla" (2000, p. 33).

La mirada del cine, y en realidad la mirada de cualquier arte, es aquella que se inscribe sobre la piel de lo real. Y a esta cualidad debe el cine su éxito, eficacia y popularidad; a esto es que se debe que el cine sea un espacio estético tan idóneo para mostrar de manera repetitiva el drama de la humana búsqueda del objeto $a$; a esto se debe que hoy en día, en la era hipermoderna del mundo-pantalla, que el arte-industria de la cinemanía se muestre como el verdadero objeto $a$.

\section{4) Algunos comentarios sobre el análisis cinematográfico, la crítica y el psicoanálisis}

Abordando de lleno el asunto del "análisis cinematográfico" y de los múltiples intentos por formalizar y aplicar distintos saberes instrumentales 
para comprender mejor una película (o aquello que le subyace), una cosa que puede deducirse de las reflexiones anteriores es que se puede tratar de analizar hasta el hartazgo la temática de tal o cual filme; desmenuzar o concentrar el análisis en algún aspecto de la película; o incluso bucear en la historia personal del director, en la forma en la que se escribió el guión o se llevó a cabo el casting, en el contexto cultural o histórico en el que se gestó el filme y, sin embargo, no es allí en donde se encontrará la "verdad" de la obra.

Entonces, según nuestra lectura, ¿dónde se puede encontrar la "verdad" del cine? Sin duda, en su temática específica, que nunca es otra que el deseo trágico que habita las subjetividades; un deseo que, en tanto trágico, siempre desemboca en lo real. No pasemos por alto que al fin y al cabo "El cine ama, adora, desea más que nada tratar el tema del deseo, dejarse tomar por todas sus formas posibles e imaginables" (Dadoun, 2000, p. 46).

Efectivamente, en las últimas décadas (especialmente a partir de los setenta ${ }^{5}$ ) ha sido muy común que el psicoanálisis haya sido utilizado como una herramienta teórica para apoyar el análisis de distintos filmes. Sin embargo, cabe hacer la pregunta: ¿Qué tipo de psicoanálisis es el que por lo regular más se "conoce"6 y se ha utilizado (en los campos de la comunicación, los estudios culturales y cinematográficos) para analizar, explicar o criticar películas? Lamentablemente, las más de las veces se ha recurrido a la versión más popularizada y vulgarizada de este saber. Como bien lo confirmó Aumont en su libro sobre el análisis del filme.

Para ser breves, diremos que esta utilización del psicoanálisis comprende esencialmente dos tipos de trabajos:

\footnotetext{
5 "Las teorías de Freud fueron discutidas más sistemáticamente en relación al cine después de la revolución post-estructuralista en teoría durante los setenta. En particular, algunos escritores han aplicado la trayectoria de Edipo a las estructuras narrativas de textos clásicos cinematográficos. Señalaron al hecho de que todas las narrativas aparentaban exhibir una trayectoria edípica; esto es, el héroe (masculino) era confrontado con una crisis en la que tenía que destacarse sobre otro hombre (con frecuencia una figura paterna) para lograr reconocimiento social y ganarse a la mujer. De esta manera, el cine fue visto para representar los trabajos de ideología patriarcal" (Creed, 1998).

${ }^{6}$ En los círculos académicos destinados a la búsqueda de respuestas fáciles y tranquilizadoras que apacigüen la angustia que genera este mundo cognitivamente viscoso y en el fondo incierto, la versión del psicoanálisis que más se "conoce" y "maneja" es el psicoanálisis de bolsillo, aquel que ha sido rebajado a un conjunto de recetas consoladoras y poco agudas, configuradas a partir de sistematizar la teoría y reducir sus conceptos fundamentales a definiciones desactivadoras de diccionario que, obturando la complejidad y criticidad de los mismos, con el paso del tiempo han logrado desgastarse y dispersarse por vía del siempre complaciente sentido común.
} 
1. Los “biopsicoanálisis", que leen la obra de un autor —en su relación con lo que se podría llamar un diagnóstico sobre ese mismo autor en tanto neurótico. El enfoque puede variar y se puede utilizar la biografía del autor en mayor o menor grado (o por el contrario, atrincherarse más o menos estrictamente en su obra), pero el objetivo es siempre el mismo: explicar una producción artística determinada mediante una determinada configuración psicológica (neurótica) [...]

2. Las lecturas "psicoanalíticas" de films, en las cuales se trata de caracterizar a este o aquel personaje como representante de tal o cual neurosis. (Aumont \& Marie, 1990, pp. 228-229)

Este tipo de análisis ligeros y hasta pobres, se basan en el llamado "psicoanálisis aplicado", que no es sino una versión instrumentalizada y muy degradada del propio psicoanálisis, utilizada -incluso a contracorriente de la propia epísteme y ética psicoanalítica- como fórmula o mera receta hermenéutica lista para aplicarse y supuestamente hacer emerger lo que está debajo de la obra fílmica.

Por esta perniciosa instrumentalización y por servir sólo para desplegar el discurso del amo, se puede argumentar que el "psicoanálisis aplicado" es un falso psicoanálisis. Como bien lo confirma la siguiente cita, Lacan, a diferencia de Freud, no creía que fuera posible e incluso deseable "que los analistas digan algo sobre la psicología del artista sobre la base de un examen de una obra de arte (véanse sus observaciones críticas acerca de la 'psicobiografía')" (Evans, 2007, p. 40). A propósito de esto, el mismo Evans, psicoanalista inglés, nos refiere que

A menudo se entiende que algunas obras de Freud implican que el psicoanálisis es un metadiscurso, un relato maestro que proporciona una llave hermenéutica general, capaz de abrir los secretos hasta entonces irresueltos de las obras literarias; en cambio, es imposible leer a Lacan como si pretendiera algo parecido. (2007, p. 41) (cursivas nuestras)

Así pues, nosotros sugerimos que cuando se trata de hacer converger psicoanálisis y cine para llevar a cabo un análisis fílmico, se debería tener mucho cuidado en no confundir, en ningún momento, a los personajes inmiscuidos en el filme (sean ficticios o reales) con los componentes estructurales de la subjetividad que el mismo filme vierte. En otras palabras: recomendamos no confundir los motivos del accionar de tal o cual personaje con la causa del mismo accionar, pues la causa siempre está más allá del lenguaje y es incognoscible, ya que pertenece al orden de lo real. Por lo mismo, nos parece una impostura pretender decir la "verdad" 
de un determinado filme a través de recurrir de forma descuidada al bagaje psicoanalítico (como si fuera posible psico-analizar una película o a los personajes que aparecen en una historia), ya que, como hemos apuntado, ni siquiera es posible esclarecer el enigma del talento creativo a través de la historia de vida de algún determinado actor o director. De hecho, "como lo repite Freud, el psicoanálisis no está en posibilidad de esclarecer el enigma del don artístico como tal" (Assoun, 2003, p. 133).

En este mismo sentido, consideramos importante que nunca se pierda de vista que las imágenes proyectadas en cualquier pantalla (de la sala oscura o la casa) están fundadas y deben su verdadero sentido a aquello que no se muestra, y eso es precisamente su materialidad impalpable; función de significantes más que de significados, ya que la imagen

... será pues también, esta imagen, aquello que no es, a saber: aquello que mostrando esconde, aquello que es implícito explicitándose, o sea todos esos elementos rechazados, ocultados, travestidos, olvidados de los cuales ella no es más que el resto, y que proceden a diseminar sus ecos silenciados a través del filme. Y ella no será, tampoco, aquello que es, o será otra cosa: aquello que escondiendo muestra, aquello que implicitándose explicita, o sea todos esos elementos a los cuales reenvían las demostraciones, confesiones, confidencias, exhibiciones funcionando como negaciones, denegaciones, camuflajes, señuelos. (Dadoun, 2000, p. 33)

El cine es, así, escenario de lo paradojal: pues lo explícito que muestra es el velo que encubre lo implícito. Y es que la materialidad de las imágenes cinematográficas está permeada por la indefinición, hilo de bordado que se desprende del énfasis en el deseo. De esta forma, el cine siempre es tensión y cada imagen es una metonimia del deseo; de lo cual bien puede desprenderse que el cine es malestar, escollo de sentido en la trama y en la imagen.

Antes de concluir este apartado, nos gustaría recalcar que el cine (invento moderno cuyas historias retratan la búsqueda del objeto $a$ ) parece puntuar e insistir en que no hay posibilidades fácticas de que el ser humano se concilie consigo mismo: las narraciones del cine confirman que no hay modo de alcanzar por fin la armonía y la tan anhelada paz social e individual. De hecho, todo intento de guardar memoria, cosa que tan bien hace el cine, parece ser un intento fallido por capturar el fluido imparable de la vida; parece ser un querer arrancarle a la muerte un poco de memoria. Como lo indicó Maier (2005, p. 72), aludiendo un poco a lo que consideramos el espíritu del cine: "sea lo que fuere que la vida nos ofrezca o nos quite, nadie puede evitar la ansiosa espera de algo indefinido, algo de lo 
que no se conoce la naturaleza, ni la función, ni porque nos resulta precioso, ni cómo defenderse de sus efectos de malestar".

\section{5) El discurso perverso del cine: la función del amo}

Para introducir de una forma que no parezca banal nuestra tesis que plantea que el discurso del cine es ante todo perverso, tenemos, primero, la necesidad de puntualizar dos cosas: presentar lo que entendemos por tal término, y reiterar que aquí, como nos estamos refiriendo al cine, apelamos sobre todo al adjetivo y no al sustantivo.

Forjado a partir del latín perversio, según Elisabeth Roudinesco el sustantivo perversión aparece entre 1308 y 1444. En cuanto al adjetivo perverso, esta autora ha señalado que "se halla atestiguado en 1190 y deriva de perversitas y de perversas, participio pasado de pervertere: volver del revés, volcar, invertir, pero también erosionar, cometer extravagancias" (2009, p. 11). Tomando en cuenta que sólo existe un adjetivo frente a varios sustantivos, debemos reconocer, entonces, que perverso se usa para señalar a aquel sujeto aquejado de perversitas, es decir, de perversidad (o de perversión).

Cabe mencionar que en psicoanálisis reconocemos, desde la perspectiva lacaniana, básicamente tres grandes estructuras subjetivas; es decir, tres diferentes modos de posicionarse como sujeto en la cultura. Dichas estructuras son: la neurótica, la psicótica y la perversa. (Es importante mencionar que todas estas posiciones son en relación con el lenguaje, o siendo más específicos, en torno a la pregunta por el deseo $^{9}$ ).

El neurótico es aquel que por definición no sabe lo que quiere. Debido a que la neurosis es "producto de un conflicto interno seguido de una represión" (Roudinesco, 2009, p. 113), la estructura neurótica se caracteriza por sufrir de no poder encontrar en la cultura aquello que por fin le daría a su vida la armonía y la estabilidad anhelada. De aquí que por lo común el neurótico sea quien con más frecuencia busca y se dirige a alguien o a algo a quien él le supone el amor y el saber pleno. El neurótico cree y crea - para sobrevivir - un Otro completo, un sistema cultural pleno de seguridades, de saberes bien cimentados con la intención, precisamente, de reprimir que no existe un tal Otro que pudiera darle lo que a todo mundo le falta. Por tal motivo, el neurótico es alguien que siempre duda; siempre se está cuestionando o demandando si está a la altura de lo que se espera

${ }^{9} \mathrm{Si}$ decimos que las tres estructuras son posicionamientos con respecto al deseo, quiere decir que son posicionamientos ante la ausencia del objeto del deseo mismo, o sea, maneras de afrontar la falta. 
de él. Incluso, cuando sus actos parecieran ser de un talante obsceno y desentendido de amarres represores, no es tanto la acción lo que define su estructura, sino su manera de afrontarla. De forma esquemática, podríamos decir que el neurótico es aquel quien en el lugar de su deseo tiene sembrada allí una pregunta más o menos invisible pero persistente. De esto se puede inferir que, según el psicoanálisis, la mayoría de los seres humanos somos neuróticos (con variantes que van, sobre todo, de la neurosis histérica, cuyo lema es el "deseo insatisfecho", a la neurosis obsesiva, cuyo lema sería "el deseo como imposible").

Por su parte, la psicosis, definida como la reconstrucción de una realidad alucinatoria, implica una estructura psíquica que experimenta la imposibilidad de acomodarse a los parámetros de la ley; y por eso es que en el psicótico hay lenguaje pero no hay discurso (el corte necesario que hace posible que el humano abandone su animalidad y piense su mundo). Si el pensamiento es "condición previa en el interior de la cual se alijan como pueden toda una serie de funciones animales" (Lacan, 2006, p. 138), la imposibilidad de que las funciones se alojen en el pensamiento, la falla radical de que eso pase, es lo que define a la psicosis. Por eso, en relación con el deseo, en el psicótico no hay pregunta, no hay duda, sino puro dolor de ser benefactor de una satisfacción que lo manda de lleno al goce y lo priva de existir. En realidad, el psicótico está en otro mundo. Al psicótico le hace falta "la falta" que posibilita la discriminación de las cosas del mundo, pues si dicha discriminación se lleva a cabo con base en el lenguaje, queda de manifiesto que en el psicótico el sistema que ordena las frases falla; no hay relación que él pueda establecer de manera convincente haciendo uso del lenguaje; de hecho, en el psicótico no hay lazo discursivo.

Vinculado con la negación de la castración, en cuanto el perverso habría que decir que éste — contrariamente al neurótico- se presenta siempre como aquel que sabe lo que quiere y que sabe cómo obtenerlo. Por ello, es complicado, o al menos no muy común, que un perverso demande ayuda de cualquier tipo, pues si él es aquel que sabe cómo funcionan las cosas, lo que hay que decir y hacer en torno a las situaciones que la vida le presenta, resulta complicado que se sienta en la necesidad de demandarle a algún otro su opinión, pues él no duda de lo que quiere. El perverso se emparienta, entonces, con la posición del legislador, del que dicta las leyes y vigila su estricto cumplimiento. En este sentido, el perverso se autopromulga poderoso, y cuando la vida lo lleva a una posición que implica, precisamente, cierto poder, suele mostrarse infranqueable. Pensemos, por ejemplo, en alguien a quien de alguna u otra forma se le debía guardar respeto u obedecer a sus órdenes porque ocupa una posición de autoridad, y pensemos también en que ese alguien disfruta 
dando órdenes, guiando, castigando y vigilando: ahí está la perversión. No se trata sólo de mandar, sino de gozar de mandar. Nos estamos refiriendo a algo que, según Freud, es una disposición y una estructura (la perversa) connatural a la mayoría de los seres humanos. "Clínicamente constituye una estructura psíquica: no se nace perverso, se deviene al heredar una historia singular y colectiva donde se mezclan educación, identificaciones inconscientes, traumas diversos. Después, todo depende de lo que cada sujeto haga con la perversión que lleva en su interior..." (Roudinesco, 2009, p. 114). Desde luego, muchos personajes harto valorados en la sociedad del entretenimiento, entre ellos, sin duda, muchos directores de cine y también un buen número de los psicoanalistas, se pueden enmarcar dentro de la estructura perversa.

Pero regresemos a nuestro tema y arriesguémonos a decir que el cine en general, y que incluso toda proyección visual que narra una historia, en el fondo son subsidiarios de la perversión. ¿Por qué afirmamos esto? Porque éstas, aunque nos hagan pensar y posibiliten la construcción de preguntas, orientan y "dictan" siempre la secuencia de las mismas. Lo que está en la pantalla es eso y no otra cosa. La forma de filmar las escenas, los diálogos, el montaje, los finales, etcétera, todo está ya armado cuando la mirada allí se vierte, y a pesar de la labor narrativa del espectador no hay espacio para la modificación de la proyección. Por ejemplo (con todo y que ahí también ya hay una historia armada), en este punto la literatura va en sentido contrario al cine, pues sin importar la historia, cada lector tiene espacio para poner en imágenes los significantes que desde su subjetividad surgen cuando se va contando la historia. El cine también es perverso - tiene un lado oscuro- en el sentido en que "El otro es quien hace posible nuestra mirada, y también quien define, en un sentido profundo, nuestro horizonte perceptivo. El otro no es un espejismo o un artificio, porque ocupa un lugar en el mundo, digamos, porque pone un mundo ante nosotros" (Lizarazo, en Echeverría et al., 2007, p. 39).

Como el afamado pensador esloveno Zizek (2006) lo indica en un interesante DVD, el cine es un arte perverso en el sentido en que indica cómo habría que desear; esto es, seduce y atrapa la mirada en un texto que no surge de la voluntad del espectador (un espectador que, por cierto, está ávido de sumergirse en la sala oscura para que le muestren o le hablen de cómo alguien más desea). Bajo esta misma línea, podemos conjeturar que los amantes del cine (los cinéfilos) son, ante todo, neuróticos que buscan vertirse en historias que de algún modo los guíen o les dicten un sentido. Dicho con más precisión: el cine resulta perverso, sobre todo si tomamos en cuenta que para el neurótico nada resulta tan atractivo como hacerse objeto de un perverso. Y es que si el neurótico siempre duda y busca a 
alguien que lo complete y lo libre del peso de sus dudas, buscar/encontrar un perverso es ideal, pues es alguien que no duda, y aun cuando hay cosas que dejan ver que se sabe en falta, hace como si él no tuviera falta, hueco, vacío o escisión, y está precisamente para rellenar todo ello.

Algunos binaristas románticos todavía dicen que el cine (particularmente el de "autor" y el "documental") está allí para provocar ideas y hacer pensar. Sin embargo, a partir de lo que hemos venido desarrollando, nosotros afirmamos que no es mecánicamente así, ya que por su disposición perversa, toda forma de cine más bien funciona como lo que rige la reflexión: esto es, propone el motivo y las formas de tratarlo. Por esta característica, para nosotros es un hecho que al igual que el cine comercial, el cine de autor y el documental son una extensión del discurso educativo (una instancia para la educación sentimental), y dadas las virtudes con las que cuenta, al mismo tiempo es un arte-industria que nos pone en riesgo de, curiosamente, apagar nuestras preguntas con base en su estimulación. Gran paradoja.

Si se duda sobre el talante perverso del cine, invitamos al lector a que trate de hacer extensiva nuestra afirmación a todo el universo cinematográfico y revise meticulosamente a partir de allí la posición que hoy en día sus protagonistas suelen tomar ante el resto de la cultura; bastará con examinar la actitud que manifiestan la mayor parte de los directores, actores, guionistas, y casi todos aquellos que sintiéndose grandes creadores y genios, participan en las distintas fases de la creación fílmica. Se confirmará que muchos de ellos actúan con cierta soberbia y glamour. Colocados no por casualidad al centro de la pantallosfera global, un buen número de la gente de cine (ocupando el sitio que algún día llegaron a tener los escritores y los filósofos) se autoperciben como los creadores nodales y más importantes de esta época, al punto que muchos de ellos se expresan con una supuesta sabiduría y visión que se ve potenciada por esta cultura visual en la que vivimos. Ellos saben bien el tipo de figuras en las que se convierten; saben que más de uno pone en ellos las respuestas a sus propias preguntas. Aunque quizá lo importante no es que pase eso (ya que también el psicoanalista, el profesor o el político se encuentran en posiciones parecidas), sino que de eso hacen precisamente su negocio y alimentan su arrogancia. Por ello, aun cuando se diga que el cine está para mostrar y evidenciar la realidad humana y, por ende, se comente que es una actividad artística noble que, sin duda, suma, pero también resta, allí se encuentra precisamente el problema: ya que como hemos apuntado, la realidad humana es inabarcable, y lo que más la determina, por lo común, es innombrable, inmostrable.

En adición a esto, si la posición perversa también se caracteriza por el uso de fetiches, resulta evidente que al estar el cine plagado de éstos, 
tenemos un elemento más para cargarle el adjetivo de un arte perverso. Hoy en día, incluso, hay fórmulas cinematográficas que se usan dentro de la industria del cine en general para hacer de un estilo o de un género enteros, fórmulas invariables que funcionan como un encantamiento, es decir, como fetiches.

\section{6) El hipercine avasallante actual: la ilusión y sus promesas}

Según Lipovetsky y Serroy (2009, pp. 16-22), en la actualidad estamos viviendo la cuarta era del cine. La primera se presentó de 1895 a finales de los años veinte (la etapa del cine mudo), y corresponde a lo que ellos denominaron su modernidad primitiva. La segunda, que tuvo lugar de 1930 a 1950, corresponde a la era de su modernidad clásica. Y la tercera, que comprende de 1950 a 1980, engloba su llamada modernidad vanguardista y emancipadora.

Configurada después de los años ochenta, y producto de la mundialización y las revoluciones tecnológicas y culturales que se han presentado en la era del acceso, la información y el entretenimiento, la cuarta fase de la historia del cine lleva la impronta de la cosmopolita y paradójica sociedad global que en los últimos años la ha germinado.

Esta cuarta fase de la historia del cine, subrayémoslo, no tiene la misma condición que las tres primeras. Mientras que éstas estuvieron por innovaciones de primer orden que en cada caso sólo afectaron a sectores delimitados, en la actualidad tenemos trastocadas todas las dimensiones del universo cinematográfico (la creación, la producción la promoción, la distribución y el consumo), al mismo tiempo y de arriba abajo. Jamás ha conocido el cine un terremoto de semejante magnitud. (Lipovetsky \& Serroy, 2009, p. 22)

Es una cuarta etapa en la cual, según Lipovetsky y Serroy, el cine se sale de la era moderna, se instala de lleno en la hipermodernidad, inicia su andadura como pantalla global y, tras ello, se planetariza y transforma en lo que estos autores han bautizado como el hipercine. Caracterizado por el exceso y por lo avasallante, por la búsqueda de la hiperrealidad y la conquista del máximo detalle, por la inclusión de realidades virtuales y la orientación a lo impactante, el hipercine es un tipo de cine que de forma paradójica

se hace con parámetros taquilleros y trasnacionales, pero también con mescolanzas y batiburrillos, con elementos cada vez más revueltos, más multiculturales. Este cine que nace con la creciente liberalización del comercio, no deja de poner en escena temas nuevos ni de sensibilizarse ante nuevas problemáticas. 
A la desregulación de los mercados mundializados le corresponde un cine global que asimila de manera creciente nuevas parcelas de sentido, ampliando sin cesar sus antiguas fronteras, desreglamentando los modelos del relato y el amor, las edades y los géneros, lo aceptable y lo inaceptable. (Lipovetsky \& Serroy, 2009, p. 24)

Marcada por el llamado cine comercial, esta cuarta etapa se distingue por ofrecer un hipercine high tech, espectacular, plurilingüe, omnitemático, taquillero, de producciones millonarias donde, por regla, se proyectan las luminarias que irradian su imagen mediática a nivel mundial. A propósito de este cine que impera glamoroso en las salas de exhibición, este cine que pretende abarcarlo y decirlo todo y que en términos temáticos hoy en día "no deja títere con cabeza", Baudrillard mencionó lo siguiente:

Citacionales, prolijos, high-tech, cargan con el chancro del cine, con la excrescencia interna, cancerosa, de su propia técnica, de su propia escenografía, de su propia cultura cinematográfica. Da la impresión de que el director ha tenido miedo de su propio filme, de que no ha podido soportarlo (o por exceso de ambición o por falta de imaginación). De lo contrario, nada explica semejante reproche de recursos y esfuerzos en descalificar su propio filme por exceso de virtuosidad. (Baudrillard, 2007, p. 13)

Frente a este hipercine pocas frases son tan certeras como la macluhiana que indica que el medio es el mensaje, y la postmanniana, que recuerda que el contenido afecta al medio. Lipovetsky y Serroy tienen razón cuando dicen que pocas veces el cine ha reflejado tan bien las revoluciones, los esfuerzos, la condición estética y las orientaciones epistémicas de nuestra sociedad. Y al igual que la ciencia, el afán por abarcar el todo es lo que distingue a muchas de las actuales megaproducciones cinematográficas.

Puede decirse sin tapujos que nuestros fílmicos días están signados por la pretensión de conocer el mayor número de experiencias; por tratar de eliminar el malestar en cuanto se manifiesta; por una supuesta democracia que está allí para garantizar la armonía del sujeto. Hay también una cierta liberación en todos los terrenos que sugestivamente plantea que el sujeto puede y debe ser feliz. Se trata de un mundo videovigilado que para todo tiende las redes de su saber objetivo y para el cual las limitaciones o los imposibles fácticos son defectos de la realidad susceptibles de saneación. El cine no escapa a todo esto; al contrario, lo reitera como medio y lo multiplica desde su trinchera narrativa, pues "el cine actual ya no conoce ni la alusión ni la ilusión: lo conecta todo de un modo hipertécnico, hipereficaz, hipervisible" (Baudrillard, 2007, p. 14), lo que indica que "toda perspectiva 
final quedó como absorbida, digerida, y no dejó otro residuo que una superficie carente de profundidad" (Baudrillard, 2007, p. 29).

El hecho de que el cine, y en realidad, el mundo de los medios, en su afán por fascinar y capturar a costa de lo que sea la atención de las audiencias, produzcan un espectáculo visual que de tanto avasallar por momentos cansa, es evidentemente un efecto del capitalismo líquido o de ficción dentro del cual vivimos. Como oportunamente lo intuyó Jean Baudrillard cuando anotó: "un libretista genial (tal vez el capital mismo) arrastró al mundo hacia una fantasmagoría de la que todos somos víctimas fascinadas" (2007, p. 32). Nos estamos refiriendo a un capitalismo dentro del cual el cine, en el contexto de las llamadas artes, ocupa un lugar tan privilegiado que varios ya lo han ubicado como el arte más importante del siglo XX. ¿Gracias a qué? A sus cualidades audiovisuales; a sus historias y estrellas suspicaces; pero sobre todo, gracias al marketing de entretenimiento y a que vivimos en una sociedad enamorada de la imagen. Se trata de un primerísimo lugar que tal vez este arte-industria sólo comparte con otra gran industria que ha marcado nuestra época: la de la música.

Por todo esto, se impone como algo necesario y sensato decir que el cine contribuye a la estimulación bochornosa de nuestra subjetividad y, por ende, puede plantearse que lejos han quedado los días en los que el cine tenía como punto distintivo sólo hacernos soñar; ahora más bien nos hipnotiza y hace todo lo posible por fascinarnos. En síntesis:

\begin{abstract}
Nuestra cultura visual se encuentra dominada por la semiótica de la exacerbación: lo que importa es la máxima visibilidad, el seguimiento paso a paso del detalle, la hiperrealidad de lo extraordinario, y de tanto reiterarse resulta totalmente imaginable [...] Hemos perdido la sutileza interpretativa, ahora necesitamos ver descompuesto y en ralentí cada uno de los momentos de desgajamiento, del choque, grano a grano de la superficie, vértigo de acciones e hiperrealidad descriptiva en una frenética del movimiento visual. (Lizarazo, en Echeverría et al., 2007, p. 43)
\end{abstract}

En este mismo sentido, podemos arriesgar otra reflexión y decir que el hipercine actual se ha vuelto pornográfico. Y no por cuestiones morales ni porque cada vez exponga más abiertamente diferentes tipo de prácticas sexuales, sino porque lo que promete a sus espectadores es "mostrarlo todo". Con imágenes desde cada vez más ángulos, con técnicas que permiten ver detalles antes invisibles, con programas que facilitan la creación de ambientes/personajes virtuales y con efectos que se han vuelto los verdaderos protagonistas de los estudios, podemos afirmar que el actual hipercine muestre o no penetraciones o la emisión de fluidos corporales, se ha vuelto simple y llanamente porno; esa es nuestra lectura. 
Y lo sostenemos en relación con dos cosas: que en su textualidad hoy se reproducen los personajes perversos que proponen que toda barrera para el ojo es franqueable; y que sus guiones y sistema de producción se proponen mostrarlo todo (al menos en lo concerniente a la parcela narrativa que abordan). También, el hipercine - ese cine de masas al que nos hemos estado refiriendo- es porno en cuanto a que dentro de su impulso neobarroco por hacer experimentar el máximo de sensaciones obtura la posibilidad del deseo en el espectador; lo sobrecarga de una hiperirrigación sensorial y sentimental que lo embrolla hasta por momentos secuestrar en él toda posibilidad de crítica:

A medida que nuestra delicadeza se embota, lo chocante, incluso lo abyecto, dejan de constituir lo exutorio de la aspiración profunda a apoderarse de lo real, y se vuelven simples objetos de consumo. A fuerza de repetidas transgresiones, el llamado arte "posmoderno" pierde todo efecto provocador y se integra perfectamente en un mercado del arte cada vez más desengañado.

(Maier, 2005, p. 44)

Pero seríamos ingratos con el cine si no señaláramos que esta tendencia exacerbada hacia lo porno (a mostrarlo todo) es propia del mundo globalizado, ya que como lo expresó el propio Baudrillard, "ya no hay pornografía localizable como tal, porque la pornografía está virtualmente en todas partes, porque la esencia de lo pornográfico se ha transmitido a todas las técnicas de lo visual y lo televisual" (2007, p. 53).

Una cosa que no hay que perder de vista es que la epistemología porno tiene su raíz en el discurso científico que trata de regular la vida moderna y del cual muchas veces nos sentimos orgullosos adeptos. Hablamos de nuevo del discurso de la ciencia y la técnica, que acertadamente lo reitera Lipovetsky al decir que:

La tecnología se ha vuelto porno: en efecto, el objeto y el sexo han entrado en el mismo ciclo ilimitado de la manipulación sofisticada, de la exhibición y la proeza, de los mandos a distancia, de las interconexiones y conmutaciones de circuitos, de las "teclas sensibles", de las combinaciones libres de programas, de la búsqueda visual absoluta. (2003, p. 168)

En estrecho vínculo con este envión científico y tecnológico, el hipercine actual predominantemente se avoca a expulsar su vómito de imágenes hiperreales; el problema es que es tan grande y tan incesante su proliferación - la cual hay que decirlo, responde a la demanda de un amplio público-, que a este hipercine le sucede lo que Baudrillard hace unos años señaló 
que le ocurría al arte todo: muere. Si esto es así de enfático es debido a que "el arte no muere porque no haya más arte: muere porque hay demasiado" (Baudrillard, 2007, p. 93). Habría que señalar que se trata de una muerte que no por ser tan anunciada es menos pretenciosa en su demostración, pues por paradójico que suene, el hipercine, aunque parezca que es el gran cuerno de la abundancia, puede conjugar su muerte con la bonanza:

La sociedad contemporánea no parece dar tiempo a las imágenes. Producimos imágenes con una asombrosa precipitación; queremos cubrirlo todo, figurarlo todo, y esto trae consecuencias: el abaratamiento icónico, la reducción casi a cero de su valor [...]. Hemos perdido, digamos, la lentitud de las imágenes y con ella su sabiduría. (Lizarazo, en Echeverría et al., 2007, p. 46)

Bien sabemos que el cine, por ser un producto cultural de cualidades excepcionales que se sustenta en la imagen, continuamente ha reflejado el estado general de la cultura misma, y lo que está sucediendo con él a principios del siglo XXI no ha sido la excepción, pues refleja muy bien $\mathrm{el}$ imperativo de goce que trajo consigo el posmodernismo. Y no olvidemos aquí que el goce, desde Lacan, no es otra cosa que un placer extremo que desemboca en el dolor, en el empacho.

En plena sintonía con el culto al Yo que impera en nuestra cultura, y en concordancia con el reinado de la yocracia, como llamara Lacan al pensamiento que se cree el dueño y amo absoluto del devenir, constatamos que los sujetos se ven llamados cada vez más en la cultura posmoderna a hacer de su derecho a una supuesta satisfacción su estilo de vida:

Por el abandono generalizado de los valores sociales que produce, por su culto a la realización personal, la personalización posmoderna cierra al individuo sobre sí mismo, hace desertar no sólo la vida pública sino finalmente la esfera privada, abandonada como está a los trastornos proliferantes de la depresión y de las neurosis narcisistas. (Lipovetsky, 2003, p. 146)

En correlación con estas afirmaciones que si bien resultan tajantes y lapidarias, Pommier se pregunta: “¿Cuál va a ser para nosotros el envoltorio de la obra, cuyo ideal consiste en dispensarnos de él?". Frente a lo que nosotros inquirimos: ¿Cuál será, pues, el envoltorio del hipercine? Sobre todo si tomamos en cuenta que:

Los aventureros de la ciencia minaron la narración, explotaron los metadiscursos, de manera que el sentido de la historia se distiende y deja que los cuerpos se desinflen como un globo. Vemos cómo se abstrae su representación artística, 
no solamente porque, como siempre, está trabajada por la negación de la nada, que le otorga su elegancia, sino porque el futuro de la historia le falta. (Pommier, 2000, P. 77)

Entonces, ¿cuál es el futuro del hipercine cuando erradica de su campo y mediante lo virtual la pesadez de lo real que le daba su talante de hablar de lo humano — no del humano idealizado — y con ello lo hacía memorable?

\section{REFLEXIONES FINALES}

Nuestra conclusión después de este largo recorrido, es que en la actualidad, el hipercine se suma a tal impulso de negación de lo singular a través de su obcecada pretensión de hacer que en sus producciones nada falte por agregar. Para nosotros, la sobreirrigación de estímulos, el avasallante discurso pornográfico y la narrativa triunfalista del "todo se puede ver", han colocado al hipercine en el corazón de la era posmoderna y en consonancia con el discurso cientificista que se guía por la tramposa ideología del "todo se puede" y "todo se vale" en pro de la diversión y la realización del humano. Se trata de una ideología posmoderna que a pesar de su eficaz extensión está condenada al fracaso y corre el riesgo de matar por sobredosis de exhibición e hiperrealismo al cine tal y como hoy lo conocemos, pues olvida que tal realización es inviable dadas las características propias de la cultura humana, que además de la violencia y el desajuste perennes, lleva impresa un sinfín de limitaciones, todas herederas de nuestra subordinación al lenguaje. Lo más grave y absurdo para el hipercine es que esta ideología en la que está enjaulado olvida que en el caso hipotético de existir la realización plena y el apoderamiento de lo real gracias a conocerlo y verlo todo, lo humano como tal caería en lo mecánico, y lo que es peor para su sociedad del espectáculo, en el aburrimiento.

\section{REFERENCIAS DOCUMENTALES}

Aceituno, R. \& Rosas, M. (comps.). (1999). Psicoanálisis. Sujeto, discurso, cultura. Santiago, Chile: Universidad Diego Portales.

Assoun, P.L. (2003). El freudismo. México: Siglo XXI.

Aumont, J. \& Marie, M. (1990). Análisis del film. Barcelona: Paidós. Baudrillard, J. (2007). El complot del arte. Ilusión y desilusión estéticas. Buenos Aires: Amorrortu.

Braunstein, N. (1999). Goce. México: Siglo XXI.

Creed, B. (1993). The monstrous-feminine: film, feminism, psychoanalysis. Routledge. . (1998). Film and psychoanalysis. En J. Hill \& P. Church (eds.), Oxford Guide to Film Studies. Londres: London University Press. 
. (2004). Freud's worst nightmare: dining out with Dr. Hannibal Lecter. En Steven Jay Schneider (ed.), The horror film and psychoanalysis: Freud's worst nightmare (pp. 188-202). Nueva York: Cambridge University Press.

Dadoun, R. (2000). Cinéma, psychanalyse et politique. París: Séguier. Echeverría, B. et. al. (2007). Sociedades icónicas. México: Siglo XXI. El cine y la memoria: ficción e historia. (1998, octubre). Revista Versión, 8. Evans, D. (2007). Diccionario introductorio de psicoanálisis lacaniano. Buenos Aires: Paidós.

Fiennes, S. (2006). The pervert's guide to cinema (DVD). Londres: P Guide Ltd.

Foucault, M. (2005). Les mots et les choses. París: Gallimard.

Gerber, D. (2005). El psicoanálisis en el malestar en la cultura. Buenos Aires: Lazos.

- (2009). ¿Por qué el deseo es inconsciente? En Casas, Constante \& Flores (coords.), Escenarios de deseo: Reflexiones desde el cine, la literatura, el psicoanálisis y la literatura (pp. 101-114). UNAM: México.

Heidegger, M. (1967). Qu'appelle-t-on penser? París: PUF.

Lacan, J. (1981). Seminario XX, Aun. Barcelona: Paidós.

. (1992). Seminario XVII. El reverso del psicoanálisis. Buenos Aires: Paidós.

_ (1988). Intervenciones y textos 2. Buenos Aires: Manantial.

- (2006). Mi enseñanza. Buenos Aires: Paidós.

Lipovetsky, G. (2003). La era del vacío: ensayos sobre el individualismo contemporáneo. Barcelona: Anagrama.

Lipovetsky, G \& Serroy, J. (2009). La pantalla global. Cultura mediática $y$ cine en la era hipermoderna. Barcelona: Anagrama.

Lizarazo, D. (2004). La fruición fílmica. Estética y semiótica de la interpretación cinematográfica. México: UAM-X.

(comp.). (2007) Icónicas mediáticas. La imagen en televisión, cine y prensa. México: Siglo XXI.

Maier, C. (2005). Lo obsceno. Buenos Aires: Nueva Visión.

Pommier, G. (2002). Los cuerpos angélicos de la posmodernidad. Buenos Aires: Nueva Visión.

- (2005). ¿Qué es "lo real”? Ensayo psicoanalítico. Buenos Aires: Nueva Visión.

Roudinesco, E. (2009). Nuestro lado oscuro. Una historia de los perversos. Barcelona: Anagrama.

Saal, F. (1997). El saber y la verdad. En N. Braunstein, El discurso del psicoanálisis. México: Siglo XXI. 